\title{
Hyperbaric oxygen therapy: implications for spinal cord injury patients with intrathecal baclofen infusion pumps. Case report
}

\author{
M N Akman MD,${ }^{1}$ P G Loubser MB ChB,${ }^{2} \mathrm{C}$ E Fife MD,${ }^{3}$ W H Donovan $\mathrm{MD}^{4}$ \\ ${ }^{1}$ Assistant Professor, Department of Physical Medicine and Rehabilitation, Inuonu \\ University Medical School, Malatya, Turkey; ${ }^{2}$ Assistant Professor, Department of \\ Anesthesiology, Baylor College of Medicine, 6550 Fannin, Suite 1003, Houston, Texas, \\ 77030, USA; ${ }^{3}$ Assistant Professor, Department of Anesthesiology, ${ }^{4}$ Professor and \\ Chairman, Department of Physical Medicine and Rehabilitation, University of Texas \\ Health Science Center Medical School, 1333 Moursund Avenue, Houston, Texas, 77030, \\ USA.
}

A patient with a cervical spinal cord injury receiving intrathecal baclofen for spasticity control underwent a 7 week course of hyperbaric oxygen therapy to induce healing of an ischial decubitus ulcer. After completion of this treatment and during a routine baclofen infusion pump refill, the actual pump reservoir volume exceeded computer measurements obtained with telemetry. Examination of the physiology of hyperbaric oxygen therapy in relation to infusion pump function revealed that the intraspinal pressures attained during hyperbaric oxygen therapy produced retrograde leakage of cerebrospinal fluid into the infusion pump reservoir.

Keywords: hyperbaric oxygen therapy; intrathecal baclofen; muscle spasticity; spinal cord injury.

\section{Introduction}

Hyperbaric oxygen (HBO) therapy is an established technology that may be utilized as the primary treatment for certain medical conditions such as carbon monoxide poisoning or decompression sickness, or as an adjunctive measure to resolve certain recalcitrant wounds. SCI patients with decubitus ulcers may be eligible for HBO therapy if the etiology of the wound is reversible tissue hypoxia. ${ }^{1}$ The continuous infusion of intrathecal baclofen via implantable infusion pumps has gained worldwide acceptance as an important new treatment modality for spasticity associated with SCI. ${ }^{2,3}$ Several types of infusion pumps exist, although those utilizing microprocessor-based technology represent the most sophisticated devices. We present the first reported use of HBO therapy for a decubitus ulcer in an SCI patient receiving intrathecal baclofen therapy for spasticity control. This report highlights the physical changes associated with HBO therapy and their impact on infusion pump function.

\section{Case report}

A 22 year old male sustained a $\mathrm{C} 4-5$ fracturedislocation during a motor vehicle accident resulting in C5 Frankel B quadriplegia. Following the SCI, the patient experienced severe spasticity which was refractory to oral medications, including baclofen, clonidine and dantrolene. Additionally, sedation and impairment of cognition were significant side effects interfering with the patient's scholastic and academic performance. Skin breakdown occurred frequently as a result of excessive skin trauma and difficulties with positioning. Subsequently, four years after the initial SCI, the patient underwent a successful temporary trial of intrathecal baclofen (Lioresal ${ }^{\circledR}$ Intrathecal, Medtronic, Inc) infusion followed by infusion pump implantation (Medtronic Synchromed ${ }^{\circledR}$ Model $8611 \mathrm{H}$ ) for long term treatment. Initial dosage of baclofen was $150 \mathrm{mcg} /$ day gradually increasing over the ensuing 8 months to $600 \mathrm{mcg} / \mathrm{day}$ to maintain 
optimal spasticity control. The patient stabilized at this dose requiring a pump refill every 8 weeks. During pump refills, $18 \mathrm{ml}$ of baclofen $2000 \mathrm{mcg} / \mathrm{ml}$ was injected percutaneously into the pump reservoir. No problems occurred with the infusion pump during this period. Accurate delivery of $0.3 \mathrm{ml} /$ day baclofen solution intrathecally was verified by correlating the residual reservoir volume at each pump refill with computer measurements obtained with telemetry.

Ten months following pump implantation, the patient developed a large full thickness ischial decubitus ulcer measuring $7 \mathrm{~cm}$ in diameter and $6 \mathrm{~cm}$ in depth with exposure of the sacrum. A trial of HBO therapy was implemented as an adjunct to definitive surgical management with hopes of minimizing the need for extensive tissue coverage and improving flap viability. This was conducted over a 7 week period during which 35 treatments were administered. During each treatment, the patient was pressurized from one to two absolute atmospheres (ATA) over 15 minutes, maintained for $1 \mathrm{~h}$ at 2 ATA and then depressurized over $15 \mathrm{~min}$ to ambient pressure while breathing $100 \%$ oxygen throughout the three phases. Some wound healing was noted on completion of this treatment course although surgical closure of the wound with a musculocutaneous flap was still indicated.

The patient received a pump refill prior to initiating HBO therapy and was scheduled for another refill on completion of the course of treatment. However, during this latter refill the residual volume aspirated from the reservoir was $16.5 \mathrm{ml}$, compared to computer estimations of less than $2 \mathrm{ml}$. No obvious reason for this discrepancy was apparent, since the patient's spasticity remained under customary control during the preceding 8 weeks. Over the next several months, no further discrepancies were detected between actual measurements and computer estimates of residual reservoir volume. The patient underwent reconstructive plastic surgery and made an uneventful recovery.

\section{Discussion}

The infusion pump described above requires an $18 \mathrm{ml}$ reservoir (Fig 1) refill every 4-12 weeks depending on the flow rate characteristics of the invidivual pump settings. The actual residual volume may be accurately determined by percutaneously aspirating fluid from the pump reservoir. A computer

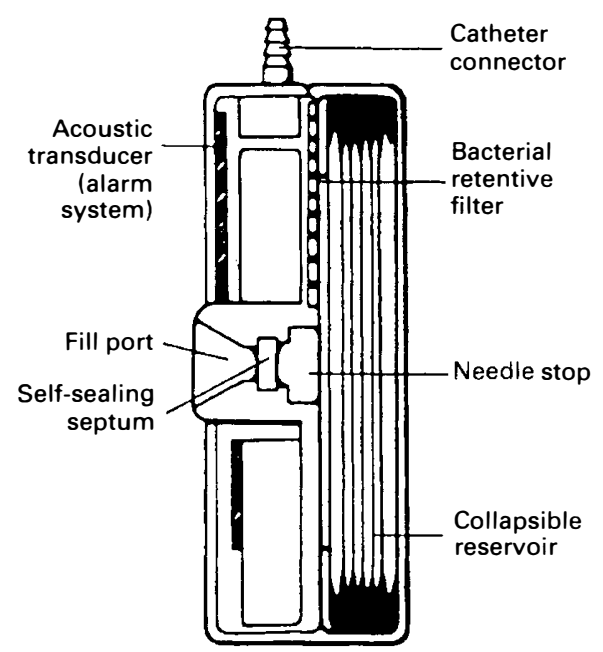

Figure 1 Side view of SynchroMed ${ }^{\circledR}$ pump

measurement of residual volume is also provided during telemetry, since a programmable microprocessor controls flow patterns within the pump. These two measures of residual reservoir volume usually correlate quite closely and verify accurate pump function. The actual pump mechanism consists of internal tubing to which a roller pump is applied (Fig 2). A stepper motor powers the roller pump to move fluid along the tubing by positive displacement, similar to peristalsis. During

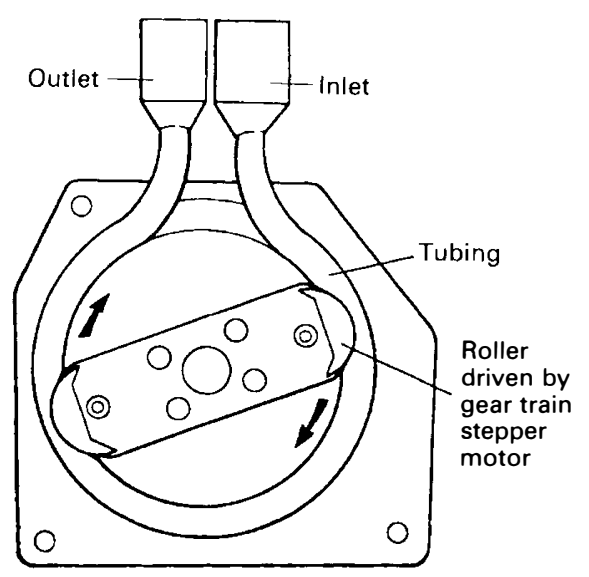

Figure 2 Roller pump mechanism 
pump refills, an intrareservoir pressure of $200 \mathrm{mmHg}$ is produced, gradually decreasing over the following weeks as the reservoir empties (Appendix 1). Care must be taken not to overfill or overpressurize the reservoir. If intrareservoir pressures exceed $400 \mathrm{mmHg}$, solution may leak past the roller pumps into the catheter attached to the pump and ultimately into the intrathecal space (Appendix 1). The reverse may occur if pressures external to the pump are high enough to promote leakage of fluid back into the reservoir. The Model $8611 \mathrm{H}$ pump does not have a valve mechanism to prevent retrograde flow, although the Model 8615 pump with an attached access side-port (used primarily for intraarterial infusion of chemotherapeutic agents, or for diagnostic purposes) incorporates a valve mechanism that prevents retrograde flow at pressures below $465 \mathrm{mmHg} .{ }^{4}$ The large discrepancy between actual and computer measurements of reservoir volume suggested that pump malfunction occurred during the course of HBO therapy.

Brown et al, ${ }^{5}$ studied minute to minute changes in intracranial (ICP) pressure or cerebrospinal fluid (CSF) pressure during HBO therapy, showing a $41 \%$ decrease in ICP during the $15 \mathrm{~min}$ pressurization from 1 to 2 ATA at $100 \%$ oxygen, followed by a return to baseline ICP during the $1 \mathrm{~h}$ at 2 ATA and a $23 \%$ increase over baseline ICP during the depressurization phase from 2 to 1 ATA. The ICP returned to pre-HBO level $15 \mathrm{~min}$ following completion of $\mathrm{HBO}$ therapy. However, the increase in CSF pressure observed by Brown et al ${ }^{5}$ would be insufficient to interfere with infusion pump function.

Theoretically, in a hyperbaric chamber pressurized to 2 ATA, the pressure within the infusion pump remains constant since the pump has a solid titanium shell. In contrast, the body equilibrates with chamber pressure so that CSF pressure will increase to 2 ATA plus $5-15 \mathrm{mmHg}$, i.e. approximately $1,530 \mathrm{mmHg}$, which signficantly exceeds intrareservoir pressure. In turn, the delivery of drug from the intrathecal catheter is impeded and retrograde leakage of CSF from the subarachnoid space into the reservoir occurs (Appendix 1).
Bench testing has further revealed that the catheter connected to the pump does not collapse when exposed to 3 ATA pressure which excludes the possibility of excessive pressure actually occluding the catheter material itself (Appendix 2).

In the above patient, as $\mathrm{HBO}$ treatments were conducted, less baclofen infused intrathecally and the concentration of baclofen within the reservoir was progressively diluted by retrograde leakage of CSF past the roller pump. These two factors should have produced a significant return of spasticity, but were counteracted by HBOinduced suppression of spasticity, a phenomenon described in several reports. ${ }^{6,7}$ In a patient receiving intrathecal morphine for intractable pain via a similar implanted pump, Baker ${ }^{8}$ reported that pain increased significantly during HBO therapy which supports our observation.

\section{Acknowledgements}

Supported in part by a grant from the National Institute on Disability and Rehabilitation Research, US Department of Education, Grant Number H133N00016-91. The authors thank Medtronic Neurological, Minneapolis, Minnesota, USA for permission to use illustrations.

\section{Appendix 1}

\section{Letter from Medtronic Neurological dated October 2, 1992 (KH-0007-93-LTR)}

'Hyperbaric chamber pressures are 760-1,000 $\mathrm{mmHg}$ above standard atmospheric pressure, or $1,520 \mathrm{mmHg}$ in absolute pressure. The pressure in the SynchroMed pump reservoir is approximately $200 \mathrm{mmHg}$ above normal atmospheric pressure, or $960 \mathrm{mmHg}$ in absolute pressure. Each pump is tested to ensure that it will not leak at twice the reservoir pressure, $400 \mathrm{mmHg}$ above atmospheric pressure or $1,160 \mathrm{mmHg}$ absolute pressure.

In a hyperbaric chamber, the pressure outside the pump, and in the body, increases to $1,520 \mathrm{mmHg}$ absolute pressure. Pressure in the spinal cord is slightly higher, but less than $2 \mathrm{mmHg}$; that is not significant and will be ignored. However, the pump is enclosed in a rigid container. The absolute reservoir pressure is not affected by external pressure, and will 
remain at $960 \mathrm{mmHg}$. The SynchroMed pump is not able to move fluid against a pressure that is $560 \mathrm{mmHg}$ above its reservoir pressure, so all output flow will cease.'

\section{Appendix 2}

Letter from Medtronic Neurological dated August 20, 1992 (KH-004-93-LTR)

'I have also run a quick test to determine if the 8703 Catheter could collapse under an external pressure of two atmospheres. The test apparatus that we used could only generate about three atmospheres of pressure above normal room pressure. The catheter tubing did not collapse at that pressure. We were not able to determine at what pressure the tubing would collapse, but it is apparently well above the pressure in a hyperbaric chamber.

I believe that in a hyperbaric chamber, the body will essentially equilibrate with the chamber pressure, i.e. CSF pressure will be two atmospheres above normal room pressure plus $10-20 \mathrm{~mm}$ of water. The CSF pressure would then be well above the pump reservoir pressure, and high enough to stop any flow from the pump.'

\section{References}

1 Davis JC (1991) Enhancement of healing. In: Camporesi EM, Barker AC, editors. Hyperbaric Oxygen Therapy - a Critical Review. Undersea and Hyperbaric Medical Society, Maryland: 127.

2 Penn RD, Savoy SM, Corcos D, Latash M, Gottlieb G, Parke B et al (1989) Intrathecal baclofen for severe spinal spasticity. N Engl J Med 320: 1517-1521.

3 Loubser PG, Narayan RK, Sandin KJ, Donovan WH, Russell KD (1991) Continuous infusion of intrathecal baclofen: Long term effects on spasticity in spinal cord injury. Paraplegia 29: 48-64.

4 Bulletin UC91012600EM (1991) Medtronic Neurological, Minneapolis, Minnesota, USA.

5 Brown JA, Preul MC, Taha A (1988) Hyperbaric oxygen in the treatment of elevated intracranial pressure after head injury. Pediatr Neurosci 14: 286-290.

6 Jain KK (1989) Effect of hyperbaric oxygenation on spasticity in stroke patients. J Hyperbaric Med 4: 55-61.

7 Kieper NR (1987) The use of hyperbaric oxygen in the rehabilitation of spinal cord injured patients due to decompression sickness. In: Kindwall EP, editor. Proceedings of the Eighth International Congress on Hyperbaric Medicine. Best Publishing Company, San Pero, California: 251.

8 Baker B (1992) Use of an implantable infusion pump in the multiplace hyperbaric chamber. Undersea Biomed Res 19: 63. 